\title{
Perceived Price Fairness in Pay-What-You-Want: A Multi-Country Study
}

\author{
Julius Bettray'1, Augustin Suessmair ${ }^{1}$, Tim Dorn ${ }^{2}$ \\ ${ }^{1}$ Leuphana University of Lueneburg, Lüneburg, Germany \\ ${ }^{2}$ Univesity of Cologne, Cologne, Germany \\ Email: julius.bettray@gmail.com, suessmair@uni.leuphana.de,tim.dorn@ymail.com
}

How to cite this paper: Bettray, J., Suessmair, A. and Dorn, T. (2017) Perceived Price Fairness in Pay-What-You-Want: A Multi-Country Study. American Journal of Industrial and Business Management, 7, 711-734.

https://doi.org/10.4236/ajibm.2017.75051

Received: March 15, 2017

Accepted: May 24, 2017

Published: May 27, 2017

Copyright $\odot 2017$ by authors and Scientific Research Publishing Inc. This work is licensed under the Creative Commons Attribution-NonCommercial International License (CC BY-NC 4.0). http://creativecommons.org/licenses/by-nc/4.0/

\begin{abstract}
The present study investigated perceived price fairness (PPF) and aimed to reveal determinants of PPF within the participative pricing mechanism paywhat-you-want (PWYW). Results support the hypothesis that PPF in PWYW conditions is higher than PPF in ordinary price setting (OPS) conditions. Determinants of PPF in PWYW conditions were identified to include both the price level and the degree of social interaction. Whereas the results conform to previous research that PPF correlates negatively with the price level in OPS conditions, this study reveals a positive correlation between the price level and PPF in PWYW conditions, which suggests that the buyer's mental model of PPF varies with the process of price determination. Therefore, future research should re-examine consequences of PPF in PWYW conditions. Additionally, results show cross-country differences of PPF and the influence of the price level on PPF.
\end{abstract}

\section{Keywords}

Perceived Price Fairness, Pay What You Want, PWYW, Willingness to Pay, Participative Pricing, Price Determination, Price Evaluation,

Perception

\section{Introduction}

The price of a product or service significantly influences customers' perception and behaviour, and therefore, pricing is a challenging but important managerial decision to make [1]. Pricing decisions carry not only the chance to differentiate from competitors, but also carry the risk of disgruntling customers [2] [3].

In 2000, online retailer Amazon tried to implement a pricing strategy where new and existing customers were being shown different prices. Amazon assumed that existing customers had lower price sensitivity than new customers and thus 
offered identical products at higher prices for existing customers. The DVD “Titus", for instance, was sold between $\$ 22.74$ and $\$ 26.24$. The price gap led to massive protests from existing customers, because they felt they were treated unequally. In the end, Amazon closed the price gap, paid the price difference of higher paid prices back, and suffered from reputational damage in the aftermath [4] [5] [6].

Not only do economic motives play an important role in a customer's price perception and a customer's ${ }^{1}$ decision to purchase a product, but so do subjective perceptions and preferences. As the example of Amazon shows, the construct of perceived price fairness (hereinafter referred to as "PPF") is a central aspect of the buyer's response to prices. PPF has a positive influence on the customer's intent to purchase [7] [8], a positive influence on customer satisfaction [9] [10], a positive influence on customer loyalty [11], and a positive influence on the buyer's attitude towards the seller [12]. Additionally, Oh [13] showed a positive correlation between PPF and perceived quality. Perceived price unfairness, however, can cause customers to feel the need to protect themselves from future unfair treatment, via complaints, return of goods, and negative word of mouth. Perceived price unfairness may also lead to sanctions by the customer, such as switching to a competing company or retaliation in court [5] [6].

The classic pricing policy aims to maximise the company's profit by appraising and determining the ideal price offer in regards to competition and customer perception. But what if customers themselves could set the price? In contrast to fixed prices, participative pricing mechanisms give customers the opportunity to contribute actively in the process of price setting.

\section{Conceptual Framework}

\subsection{Pay-What-You-Want}

The pricing mechanism pay-what-you-want (hereinafter referred to as "PWYW") provides for a special form of customer participation. In PWYW situations, the "buyer's control over the price setting is at a maximum level; the buyer can set any price above or equal to zero, and the seller cannot reject it" [14]. In recent history, there have been many studies on applicability, benefits, and influential determinants in PWYW situations, as summarised in the following.

Decisive for the success of a PWYW offer are the characteristics of the product offered. Kim, Natter, and Spann [15] assume that in PWYW situations, price paid increases by just 20 percent of the increase in variable costs. Moreover, offering PWYW decreases the average price paid but also increases the amount of customers [14] [16]. As such, PWYW is suitable for short-term offers and promotions rather than applicable as a permanent pricing strategy and is more dedicated for products with high fixed and low variable costs [14] [15]. A good example for the successful application of PWYW would be a restaurant that is

${ }^{1}$ For the sake of simplicity, the masculine form is used throughout this document, but should be taken to refer to persons of any gender. 
temporarily not running at full capacity [14] [16] [17]. Introducing the participative pricing mechanism as a time-limited promotion could help use up spare capacity and help win new customers, segueing from applicability to benefits of PWYW.

Customers generally prefer participative pricing mechanisms to conventional pricing mechanisms [14] [18] [19]. Chandran and Morwitz [18] stated that customers who perceive a high level of control in the process of price determination also show higher intentions to purchase. This is in line with findings of Haws and Bearden [20], who reported that customers are more likely to pay a price if they were actively participating in the price building process. Additionally, PWYW can attract new customers due to its innovative and unconventional character [14].

If customers acted fully rationally and followed the concept of homo oeconomicus, they would extensively use their chance of free-riding and never pay a price above zero [21]. However, people do pay a price significantly higher than zero [14] [19] [22] [23] [24] [25]. Up until now, ten determinants have been identified to influence the customer's willingness to pay in PWYW situations. Kim et al. [14] identified altruism, fairness, income, loyalty, price consciousness, reference price, and satisfaction as influential determinants. More recently Kim, Kaufmann, and Stegemann [26] added the construct "high level of reputation" to the list of influential determinants. Hilbert and Suessmair [27] added to the list by indicating that social norm compliance influences a customer's willingness to pay, although their results were not statistically significant. Subsequently, Dorn and Suessmair [28] showed the positive effect of personal interaction on a customer's willingness to pay during a payment situation in the PWYW context.

\subsection{Perceived Price Fairness}

Fairness is a strong determinant that influences the buyer's willingness to pay in PWYW situations [29]. Whereas fairness as a determinant represents the influence of the buyer's willingness to be fair on prices paid, PPF refers to a buyer's assessments of whether a seller's price is reasonable, acceptable or justifiable [6] [30]. Considering the price setting process in PWYW situations, the concepts of $\mathrm{PPF}$ and fairness as influential determinants overlap. However, since fairness is just one of many influential determinants of willingness to pay in PWYW situations, the willingness to pay a fair price does not necessarily result in a price paid which the buyer perceives as fair. PPF in the PWYW context has to be examined yet.

Until today, there is no unique definition of PPF [5] [31]. However, what all existing definitions have in common is that they are based on one or more of the three socio-psychological theories: The dual entitlement principle, the equity theory, and the theory of cognitive dissonance. The dual entitlement principle by Kahneman, Knetsch, and Thaler [32] [33] is a theory of procedural justice that points to the question of whether or not price-determining processes refer to 
general standards and rules. This principle is mainly used to assess price increases [5]. According to the equity theory, distributive justice is realised when the rewards minus the costs divided by the investments of one party are equal to the rewards minus the costs divided by the investments of the other party [34] [35] [36]. ${ }^{2}$ Following this theory, the buyer's price fairness perception depends on his perceived input-output ratio compared to all involved reference points such as previous purchases and other buyers [5]. Festinger's [37] theory of cognitive dissonance can explain buyers' reaction to perceived price unfairness. The theory assumes that people seek internal consistency and that disparity in a buyer's perceived input-output ratio causes cognitive dissonances. The massive protests by existing customers in the previous example of Amazon illustrate people's reactions to such cognitive dissonances, trying to restore their cognitive balance again [5].

Although there is no unique definition of PPF, existing literature can be categorised according to their different approaches. The majority of studies attribute the concept of a "reference price" to play a central role in the buyer's price fairness perceptions [6] [12] [38]-[45]. Xia et al. [6], for instance, stated that "price fairness judgments involve a comparison of a price or procedure with a pertinent standard, reference, or norm" (p. 1) and Frey and Pommerehne [41] pointed out that buyers are "evaluating 'fairness' with reference to an adaptively determined 'just price”" (p. 296). According to Padula and Busacca [46], however, PPF "can be defined as the consumers' judgement of whether the actual price is 'just' compared to his assessment of the economic value that the supplier has captured from the exchange relationship with him" (p. 34). This is in line with Bolton et al. [39] and Martins and Monroe [47], who also considered the seller's reference profit as decisive for the buyer's PPF. Kalapurakal, Dickson, and Urbany [48] and Oh [13] argued that reference transactions play "an extremely important role in shaping such (price fairness, remark of the author) perceptions" [48]. Whereas previously mentioned authors focused on comparisons with reference prices, the seller's profit, or reference transactions, Bearden [20] and $\mathrm{Ku}$ kar-Kinney et al. [30] saw the seller's absolute price as the crucial factor for the buyer's PPF. Interestingly, Dickson and Kalapurakal [49] believed that buyer's "perceptions about price fairness are affected not only by the observed price level (outcome) but also by the price-rule (process) that generates it: a fair price is one that results from a fair pricing rule" (p. 430), which means that the buyer's evaluated PPF in a PWYW situation allows conclusions to be drawn on price fairness in general within the pricing mechanism PWYW.

\subsection{Formulation of the Hypotheses}

Dorn [29] assumed that in PWYW situations, the buyer's price fairness perception is at a maximum level because the buyer can independently determine the price. This assumption builds on studies by Weiner [50], Chandran

${ }^{2}$ Distributive justice is realised, when $\frac{\text { rewards of } A-\operatorname{costs} \text { of } A}{\text { investments of } A}=\frac{\text { rewards of } B-\operatorname{costs} \text { of } B}{\text { investments of } B}$. 
and Morwitz [18], and Haws and Bearden [20]. They showed that customers perceive a price as fairer if they are participating in the price setting process (compared to a company-determined fixed reference price, even if the self-determined price is higher). Chandran and Morwitz [18] additionally noted that the buyer's opportunity to participate in the price setting process increases his satisfaction and leads to a higher intention to purchase. Although it is widely believed that the price building mechanism PWYW implies a high PPF, this has not been empirically tested yet. This study is the first to investigate PPF in a PWYW context.

$\mathrm{H}_{1}$ : PPF in a PWYW context is significantly higher than PPF in an ordinary price setting context.

Additionally, this study aims to identify influential determinants of PPF in a PWYW context. Several determinants have already been identified for PPF, but only within ordinary price setting (hereinafter referred to as "OPS") conditions. Not all of them are potential determinants in PWYW conditions. Many studies focused on determinants influencing the buyer's PPF when the seller increases the price of a product or service [30] [32] [33] [38] [39] [40] [41] [51]-[60]. However, because there are no price changes by the seller in PWYW situations, determinants for PPF in the case of price increases are irrelevant for this study. Also not relevant for PPF within PWYW are studies regarding geographic price differentiation [42], time-related price differentiation [43], or any other price differentiation [61]-[66], simply because the seller does not determine the price. Potential influential determinants of PPF in PWYW situations are the price level, the degree of social interaction, and the buyer's cultural background.

Kamen and Toman [67] investigated the influence of the price level on PPF. They developed the fair price theory, which states that a buyer has a fair price for a product or service in mind when he purchases it and that he is unwilling to pay a higher price. In line with the fair price theory, Bearden et al. [68] as well as Maxwell [69] assumed a negative correlation between the price level and PPF. This assumption will be tested in both OPS and PWYW conditions.

$\mathrm{H}_{2 \mathrm{a}}$ : PPF correlates negatively with the amount paid in OPS conditions.

$\mathrm{H}_{2 \mathrm{~b}}$ : PPF correlates negatively with the amount paid in PWYW conditions.

Kim et al. [14] suggested that in PWYW situations, the social distance between the buyer and seller plays a significant role in the buyer's price determination. Subsequently, Dorn and Suessmair [28] provided evidence that, in PWYW, the "amount of social presence and personal interaction" (p. 14-15) significantly influences the buyer's perception and behaviour due to "the impact of the influential construct social agreeableness on a PWYW decision". Although there haven't been any studies investigating the influence of the degree of social interaction on PPF, the literature on PWYW suggests that this may be an important factor influencing the buyer's PPF.

$\mathrm{H}_{3}$ : The buyer's PPF in a PWYW situation varies with the degree of social interaction.

As this study was conducted in several countries, differences in PPF in 
PWYW situations between countries shall be examined. While both PPF and PWYW are relatively well investigated constructs, only few studies dealt with one of the constructs in a multi-country environment. It can be assumed that people from different sociocultural backgrounds differ in their perception of price fairness. Indeed, Mattila and Choi [70] showed different price fairness perceptions between South Korean and US consumers and Bolton et al. [71] provided evidence for "cultural differences in perceptions of price fairness" (p. 574) between Chinese and US consumers. Because influential determinants for PPF in PWYW situations may be more or less valid across cultures, differences between countries will be examined.

$\mathrm{H}_{4 \mathrm{a}}$ : The influence of price level on the buyer's PPF in a PWYW context varies between countries.

$\mathrm{H}_{4 \mathrm{~b}}$ : The influence of the degree of social interaction on the buyer's PPF in a PWYW context varies between countries.

\section{Research Design}

\subsection{Methodology}

Widely applied in research on PPF, a questionnaire was used for investigating PPF in a PWYW context [20] [39] [40] [41] [42] [48] [52] [54] [58] [60] [63] [68] [69] [72]-[79]. As this study was conducted in several countries, the questionnaire was set up online and was available simultaneously in all countries between $22^{\text {nd }}$ of July and $25^{\text {th }}$ of August 2015. ${ }^{3}$ The survey launched in Australia, Chile, China, Germany, Italy, Japan, Poland, Qatar, Singapore, United Arab Emirates, and the United States of America and was distributed via mailing lists from universities, research forums, and academic Facebook groups. Hence, most of the participants were students and members of universities. Prior to the data collection, a minimum sample size of 100 respondents per country was defined; sufficient data was collected in Australia $(n=132)$, Germany $(n=121)$, Poland $(n=103)$ and the USA $(n=123)$.

To collect bias-free data across countries, a homogeneous reference product was needed, which is standardised, comparable, and equal for all participants across countries. McDonald's Big Mac was chosen as the reference product due to its popularity and standardisation all over the world. The Big Mac has already been an object of investigation in research. In 1986, The Economist magazine introduced the Big Mac Index, a survey that uses the price of a Big Mac as a benchmark to measure the purchasing power parity between countries. Consequentially, McDonald's Big Mac suits well as the reference product for the purpose of this study.

\subsection{Structure and Contents of the Questionnaire}

Because of the international distribution of the survey, the questionnaire was set up in English. The questionnaires were identical across countries, only differing ${ }^{3} \mathrm{~A}$ pre-test prior to the launch solely suggested using home currencies for each country instead of using US-Dollars for all countries. 
in terms of the currency used.

Firstly, it was declared that all information will be treated confidentially. Then, the participant was asked if he has ever eaten McDonald's Big Mac, in order to exclude people who do not know the reference product.

Afterwards, the participant was familiarised with PWYW pricing and had to indicate his willingness to pay for a Big Mac in a PWYW situation. Prior to opening with the survey, the participant was randomly subdivided into one of three scenarios. The scenarios only differed in the degree of social interaction during the payment evaluations. ${ }^{4}$ All scenarios referred to McDonald's offering a special deal due to its $100^{\text {th }}$ birthday, enabling customers to pay a self-determined price for a Big Mac. The participant could pay online and anonymously, resulting in a print-out voucher for the Big Mac (Scenario 1), pay for the Big $\mathrm{Mac}$ at the counter in a McDonald's restaurant in direct contact with McDonald's employees when only the McDonald's employee is watching the payment (Scenario 2), or pay the Big Mac at the counter in a McDonald's restaurant in direct contact with McDonald's employees when the McDonald's employee as well as a couple of friends are watching the payment (Scenario 3).

Hereafter, the PPF in the PWYW situation was queried. Monroe [80] argued that price fairness simply is a subjective perception of whether a price is fair or not. Traditionally, PPF was seen as a multidimensional concept which encompasses the two dimensions of distributive price fairness ${ }^{5}$ and procedural price fairness $^{6}$ [57] [81]. However, Chung and Petrick [1] suggested "that individuals tend to perceive price fairness globally, rather than attribute to specific outcomes and procedures" (p. 918). In line with a majority of studies, PPF was recorded as a single-item-measurement [8] [32] [39] [40] [49] [52] [53] [64] [69] [72] [78]. The participant was asked "How fair was the price I paid for the Big Mac in the previous situation?" PPF was rated on a 7-point Likert scale (1: "Unfair" to 7: "Fair"). Following Xia et al. [6] and to validate the single-item-measurement, the participant was also asked if the price paid was "adequate" and "justified". As "fair" correlated statistically significantly with both "adequate" $(r(320)=0.83, p$ $<0.01)$ and "justified" $(r(320)=0.70, p<0.01)$, the single-item-measurement can be seen as valid.

The participant was then asked for the price he had to pay the last time he bought a Big Mac: "What did you pay for a Big Mac the last time you went to McDonald's?" Afterwards the participant had to indicate his PPF of this price in OPS conditions.

The questionnaire concluded by asking for additional information such as the participant's knowledge about PWYW and his perception about McDonald's. Finally, demographical data of the participant was collected.

\footnotetext{
${ }^{4}$ Since the degree of social interaction in a PWYW context significantly influences the buyer's willingness to pay, using various scenarios is a "commonly used methodological approach for assessing situational differences of a PWYW decision" [29].

5"representing price outcome per se" [1].

6"emphasizing the price setting process" [1].
} 


\subsection{Data Preparation}

For bias-free results, the data had to be adjusted. As mentioned before, participants who did not know the Big Mac were excluded from further evaluations. ${ }^{7}$

Outliers, which could bias the results, had to be identified and excluded accordingly. Since the participants indicated their PPF via Likert scales, only the buyer's willingness to pay in the PWYW situation as well as his reference price had to be tested for outliers. Outliers were not selected using Tukey's rule [82], but with a more recent method following Carling [83] instead. He proposed "an improvement of the Boxplot rule by including the sample median in the linear combination of order statistics, rather than only the first and the third quartiles" (p. 250). Cut-off points for subjects were determined via

$$
c^{U}=q_{2} \pm \frac{17.63 n-23.64}{7.74 n-3.71} *\left(q_{3}-q_{1}\right)
$$

where $c^{U}$ is the cut-off point, $q_{2}$ is the median, $n$ is the sample size, and $q_{3}$ and $q_{1}$ are the sample quartiles.

At the end of this screening process, $n=322$ with an average age of 25.68 ( $S D$ $=7.59$ ) years remained out of the initial sample size of $n=479$. Excluding the data of 157 subjects looks questionable at first glance, but the majority of excluded data was due to subjects who did not indicate a reference price, which accounted for 124 cases. ${ }^{8}$ The remaining subjects were divided into groups as listed in Table 1.

As a last step, a standardisation of the different currencies was necessary, since Australian participants indicated their willingness to pay and reference price in Australian Dollars, German subjects in Euros, Polish participants in Zlotys, and US citizen in US-Dollars. Because currency exchange rates vary on a daily basis, an alternative approach was used to standardise the data. As The Economist frequently publishes the Big Mac's national price in the country's home

Table 1. Group allocation of subjects.

\begin{tabular}{cccccc}
\hline & Australia & Germany & Poland & USA & Grand total \\
\hline Scenario 1 & 21 & 34 & 21 & 29 & 105 \\
Female & 12 & 18 & 11 & 15 & 56 \\
Male & 9 & 16 & 10 & 14 & 49 \\
Scenario 2 & 27 & 22 & 27 & 31 & 107 \\
Female & 17 & 12 & 14 & 14 & 57 \\
Male & 10 & 10 & 13 & 17 & 50 \\
Scenario 3 & 29 & 27 & 24 & 30 & 110 \\
Female & 18 & 13 & 11 & 12 & 54 \\
Male & 11 & 14 & 13 & 18 & 56 \\
Grand Total & 77 & 83 & 72 & 90 & 322 \\
\hline
\end{tabular}

${ }^{7}$ Three subjects from Australia, Poland, and the USA were excluded from the data.

${ }^{8}$ The outlier analysis was conducted after subjects without indicated reference prices were excluded. 
currency and in US-Dollar, the most recent national reference price for McDonald's Big Mac could be gathered from a reliable source. ${ }^{9}$ To standardise the data, each subject's willingness to pay as well as his last remembered reference price was set in relation to the true reference price in his country (i.e. how many percent of the national reference price did the subject indicate as his willingness to pay or as his remembered reference price). Then this relation was multiplied with the true reference price of the USA, to convert all prices into US-Dollars. ${ }^{10,11}$

\section{Results}

All statistical tests were conducted with a significance level of $\alpha=0.05$. Widely accepted in research, Likert scales were treated as interval scales [84] [85]. Underlying assumptions for each statistical test is checked in the respective section. However, the central limit theorem allows for the assumption that the data is normally distributed. "[In] large samples the estimate will have come from a normal distribution regardless of what the sample or population data look like" [86]. According to Field [86], the data is normally distributed if the sample size is larger than 30. Accordingly, normal distribution in the sample of this study was assumed as indicated in Table 2.

\subsection{Hypothesis 1}

Because the same participants indicated both their PPF in PWYW and their PPF in OPS conditions, a paired-samples t-test was conducted to test the first hypothesis. On average, PPF in PWYW $(\mathrm{M}=4.55, \mathrm{SD}=1.80)$ was higher than PPF

Table 2. Descriptive statistics across all countries and scenarios.

\begin{tabular}{|c|c|c|c|c|c|c|}
\hline \multicolumn{7}{|c|}{ Descriptive statistics } \\
\hline & \multirow{2}{*}{$\begin{array}{c}\text { N } \\
\text { Statistic }\end{array}$} & \multirow{2}{*}{$\begin{array}{c}\text { Minimum } \\
\text { Statistic }\end{array}$} & \multirow{2}{*}{$\begin{array}{c}\text { Maximum } \\
\text { Statistic }\end{array}$} & \multicolumn{2}{|c|}{ Mean } & \multirow{2}{*}{$\begin{array}{c}\text { Std. Deviation } \\
\text { Statistic }\end{array}$} \\
\hline & & & & Statistic & std. error & \\
\hline PPF in PWYW & 322.00 & 1.00 & 7.00 & 4.55 & 0.10 & 1.80 \\
\hline PPF in OPS & 322.00 & 1.00 & 7.00 & 3.61 & 0.09 & 1.59 \\
\hline Indicated price: PWYW & 322.00 & 0.00 & 6.00 & 2.11 & 0.08 & 1.37 \\
\hline Indicated price: OPS & 322.00 & 2.00 & 7.48 & 4.59 & 0.06 & 1.11 \\
\hline Age & 322.00 & 15.00 & 78.00 & 25.68 & 0.42 & 7.60 \\
\hline Valid $N$ (listwise) & 322.00 & & & & & \\
\hline
\end{tabular}

${ }^{9}$ Data retrieved from: http://www.economist.com/content/big-mac-index, assessed on August 27th, 2015.

${ }^{10}$ Subject's standardised price $=\frac{\text { subject's indicated price }}{\text { national reference price }} *$ reference price USA .

${ }^{11}$ For instance: If a subject from Poland indicates to pay 6.00 Zloty for a Big Mac and the national reference price in Poland is 9.60 Zloty, he indicates a price of $62.50 \%$ of the Polish reference price. This relation multiplied with USA's reference price of 4.79 US-Dollar for a Big Mac leads to the subject's standardised willingness to pay of approximately 2.99 US-Dollar. 
in OPS conditions $(\mathrm{M}=3.61, \mathrm{SD}=1.59)$ as indicated in Table 3. This overall difference of $0.94,95 \%$ CI $[0.73,1.16]$, was highly statistically significant, $\mathrm{t}(321)$ $=8.59, \mathrm{p}<0.001$, and represented a medium-sized effect, $\mathrm{d}=0.59 .^{12}$

\subsection{Hypothesis 2a}

A Pearson product-moment correlation test was conducted to examine $\mathrm{H}_{2 \mathrm{a}}$. As demonstrated in Table 4, the Pearson correlation coefficient $r(322)=-0.13, p=$ 0.019 with $R^{2}=0.017$ showed a significant negative correlation between PPF and the amount paid in OPS conditions. Because a correlation is based on linearity and the correlation coefficient gives no indication if the relationship between the variables is perfectly linear, the graphical tool Loess was also used to more precisely analyse the relation between the two variables. Loess is non-parametric and consequently does not contain any assumptions like linearity. Jacoby [87] pointed out that "loess-enhanced scatter plots often reveal relatively complex relationships that could easily be overlooked with traditional statistical modelling procedures" (p. 578). The loess curve-see Figure 1 illustrated that PPF in OPS decreased up to an amount of approximately $\$ 5$, before it marginally increased.

Table 3. One-sample $t$-test for a comparison of the means of PPF in PWYW and PPF in OPS across all countries.

\begin{tabular}{|c|c|c|c|c|c|c|}
\hline \multicolumn{7}{|c|}{ One-sample test } \\
\hline & \multicolumn{6}{|c|}{ Test value $=0$} \\
\hline & \multirow{2}{*}{$t$} & \multirow{2}{*}{ df } & \multirow{2}{*}{$\begin{array}{c}\text { Sig. } \\
\text { (2-tailed) }\end{array}$} & \multirow{2}{*}{$\begin{array}{c}\text { Mean } \\
\text { difference }\end{array}$} & \multicolumn{2}{|c|}{$95 \%$ confidence interval of the difference } \\
\hline & & & & & Lower & Upper \\
\hline $\mathrm{PPF}$ in $\mathrm{PWYW}$ & 45.407 & 321 & 0.000 & 4.5497 & 4.353 & 4.747 \\
\hline PPF in OPS & 40.607 & 321 & 0.000 & 3.6056 & 3.431 & 3.780 \\
\hline
\end{tabular}

Table 4. Pearson correlation between the buyer's PPF in OPS and his indicated price in OPS.

\begin{tabular}{|c|c|c|c|}
\hline \multicolumn{4}{|c|}{ Correlations } \\
\hline & & Indicated price: OPS & PPF in OPS \\
\hline \multirow{4}{*}{ indicated price: OPS } & Pearson correlation & 1 & $-0.131^{*}$ \\
\hline & Sig. (2-tailed) & & 0.019 \\
\hline & $\mathrm{N}$ & 322 & 322 \\
\hline & Pearson correlation & $-0.131^{*}$ & 1 \\
\hline \multirow[t]{2}{*}{ PPF in OPS } & Sig. (2-tailed) & 0.019 & \\
\hline & $N$ & 322 & 322 \\
\hline
\end{tabular}

${ }^{\star}$ Correlation is significant at the 0.05 level (2-tailed).

${ }^{12}$ Australia $(t(76)=3.03, p=0.003)$, Germany $(t(82)=5.50, p<0.001)$, Poland $(t(71)=4.58, p<$ $0.001)$, USA $(t(89)=4.17, p<0.001)$. 


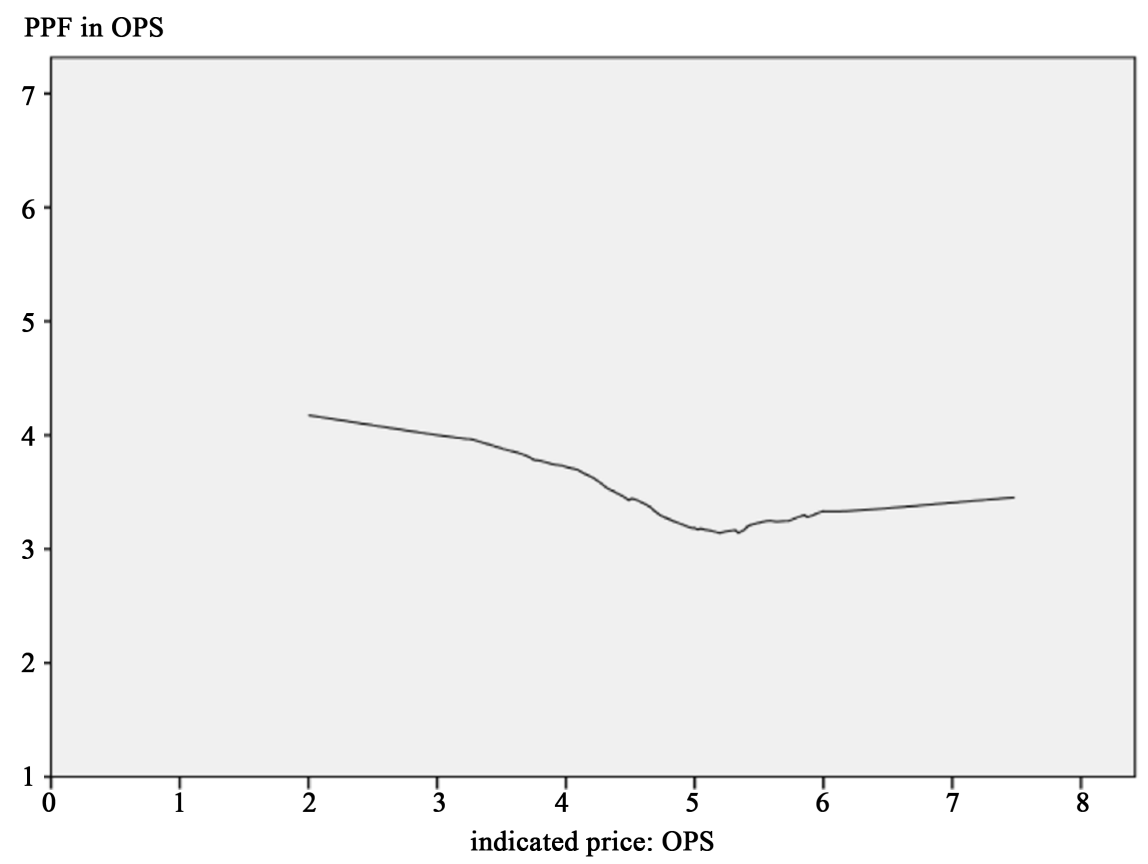

Figure 1. Relationship between the buyer's PPF and his indicated price in OPS. Loess, $f=$ 0.5 .

\subsection{Hypothesis $2 \mathrm{~b}$}

The Pearson correlation to investigate $\mathrm{H}_{2 \mathrm{~b}}$ resulted in a statistically significant positive correlation coefficient $r(322)=0.25, p<0.001$ with $R^{2}=0.062$ as indicated in Table 5. As shown by the loess curve in Figure 2, PPF in PWYW strongly increased up to an indicated price of roughly $\$ 1$, then slightly increased up to an amount of approximately $\$ 3$ before PPF very slightly decreased continuously.

\subsection{Hypothesis 3}

For examining $\mathrm{H}_{3}$, a one-way independent ANOVA was conducted, see Table 6. The buyer's PPF was defined as the dependent variable and the scenario as factor. Because the data comprised of three independent samples and Levene's test indicated equal variances $(F(2,319)=0.50, p=0.61)$, the one-way ANOVA was conducted without any restrictions.

As illustrated in Table 7, analysis of variance showed a main effect for scenario on PPF in PWYW, $F(2,319)=7.16, p=0.001, \eta^{2}=0.043$. Post hoc analyses using Duncan's new multiple range test indicated that PPF was lower for participants in a scenario with a low degree of social interaction $(M=4.04, S D=$ 1.83) than for participants in scenarios with a medium $(M=4.66, S D=1.70)$ and high degree of social interaction $(M=4.93, S D=1.76)$. PPF did not differ significantly between participants in scenarios with a medium and a high degree of social interaction.

\subsection{Hypothesis 4a}

To check $\mathrm{H}_{4 \mathrm{a}}$, the correlation coefficients of all countries were converted to $Z_{r}$ in 


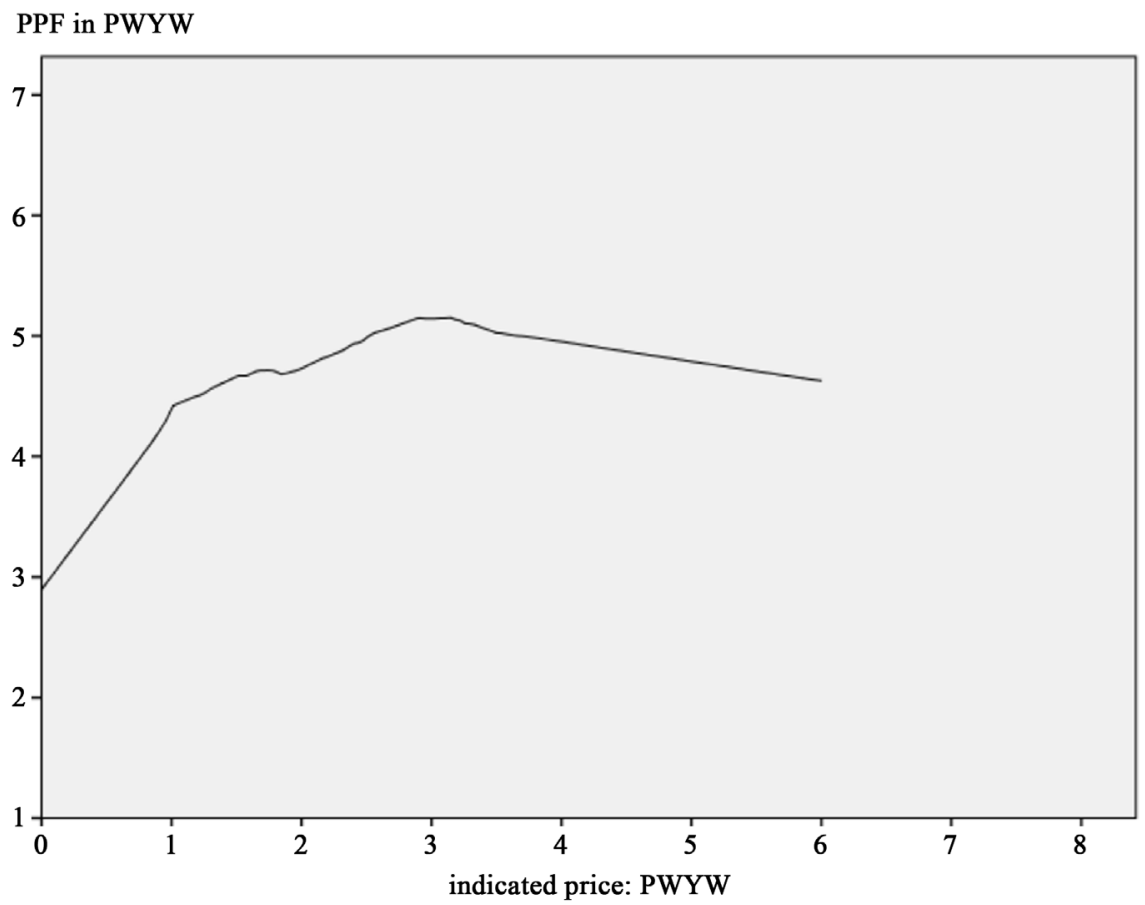

Figure 2. Relationship between the buyer's PPF and his indicated price in PWYW. Loess, $f=0.5$.

Table 5. Pearson correlation between the buyer's PPF in PWYW and his indicated price in PWYW.

\begin{tabular}{cccc}
\hline \multicolumn{3}{c}{ Correlations } \\
\hline & PPF in PWYW & Indicated price: PWYW \\
\hline PPF in PWYW & Pearson correlation & 1 & $0.248^{* *}$ \\
& Sig. (2-tailed) & & 0.000 \\
N & 322 & 322 \\
Indicated price: PWYW & Sig. (2-tailed) & $0.248^{* *}$ & 1 \\
& $\mathrm{~N}$ & 0.000 & 322 \\
\hline
\end{tabular}

${ }^{* *}$ Correlation is significant at the 0.01 level (2-tailed).

Table 6. ANOVA for differences between PPF per scenario.

\begin{tabular}{cccccc}
\hline \multicolumn{5}{c}{ ANOVA } \\
\hline \multicolumn{5}{c}{ PPF in PWYW } \\
\hline Sum of squares & df & Mean square & $F$ & Sig. \\
\hline Between groups & 44.551 & 2 & 22.276 & 7.155 & 0.001 \\
Within groups & 993.154 & 319 & 3.113 & & \\
Total & 1037.705 & 321 & & & \\
\hline
\end{tabular}


Table 7. PPF per scenario via a Duncan post hoc test

\begin{tabular}{cccc}
\hline \multicolumn{3}{c}{ PPF in PWYW } \\
\hline \multirow{3}{*}{ Scenario } & $N$ & \multicolumn{2}{c}{ Duncan $^{\mathrm{a}, \mathrm{b}, \mathrm{c}}$} \\
\cline { 3 - 4 } & 105 & \multicolumn{2}{c}{ Subset } \\
\hline 1 & 107 & & 2 \\
2 & 110 & & 4.038 \\
3 & & & 4.964 \\
Sig. & & 1.000 & 0.268 \\
\hline
\end{tabular}

Means for groups in homogeneous subsets are displayed based on observed means. The error term is Mean Square $($ Error $)=3.024$. a. Uses Harmonic Mean Sample Size $=107.294$. b. The group sizes are unequal. The harmonic mean of the group sizes is used. Type I error levels are not guaranteed. c. Alpha $=0.05$.

order to make the sampling distribution normal and to know the standard error. Subsequently, the $z$-score of the difference between the converted correlation of one country versus another country indicated the two-tailed $p$-value. ${ }^{13}$

The correlation between price level and PPF, listed in Table 8, was significantly different between Poland $(r=0.47)$ and the USA $(r=0.18), z=2.01, p=$ 0.044 and Poland and Germany ( $r=0.13), z=2.32, p=0.02$.

Subsequently, the loess curve for the relation between indicated price and PPF in Poland (Figure 3) was generated to investigate the correlation of the price level and PPF in the country with the highest correlation coefficient more precisely. Compared with the overall curve of $\mathrm{H}_{2 \mathrm{a}}$, the increase of PPF up to an amount of approximately $\$ 2.5$ was steeper. After an approximately constant level of PPF between prices of $\$ 2.5$ and $\$ 3$, similar to the overall loess curve, PPF in Poland dropped more rapidly compared to the overall course.

\subsection{Hypothesis 4b}

A $3 \times 4$ two-way independent ANOVA was conducted to investigate whether the influence of the degree of social interaction on the buyer's PPF varies between countries. Scenario and country were defined as independent variables and the dependent variable was PPF. Levene's test indicated equal variances $(F(11,310)$ $=0.81, p=0.63$ ).

The ANOVA (Table 9) showed significant main effects for both scenario $(F(2$, $\left.310)=8.80, p<0.001, \omega^{2}=0.054\right)$ and country $\left(F(3,310)=4.55, p=0.004, \omega^{2}=\right.$ 0.042). Duncan's new multiple range test (Table 10 and Table 11) revealed that buyer's PPF was significantly lower in scenario $1(M=4.04, S D=1.83)$ compared to Scenario $2(M=4.66, S D=1.70)$ and Scenario $3(M=4.93, S D=1.76)$. There was no significant difference of PPF between scenario 2 and 3. Looking at the main effect of the variable country (Figure 4$)$, PPF in the USA $(M=4.99, S D$ $=1.74)$ was significantly higher than PPF in Poland $(M=4.04, S D=1.98)$. Australia $(M=4.49, S D=1.79)$ and Germany $(M=4.57, S D=1.59)$ did not differ significantly from either Poland, the USA, or each other.

${ }^{13}$ This approach is based on Field [86]. 
PPF in PWYW

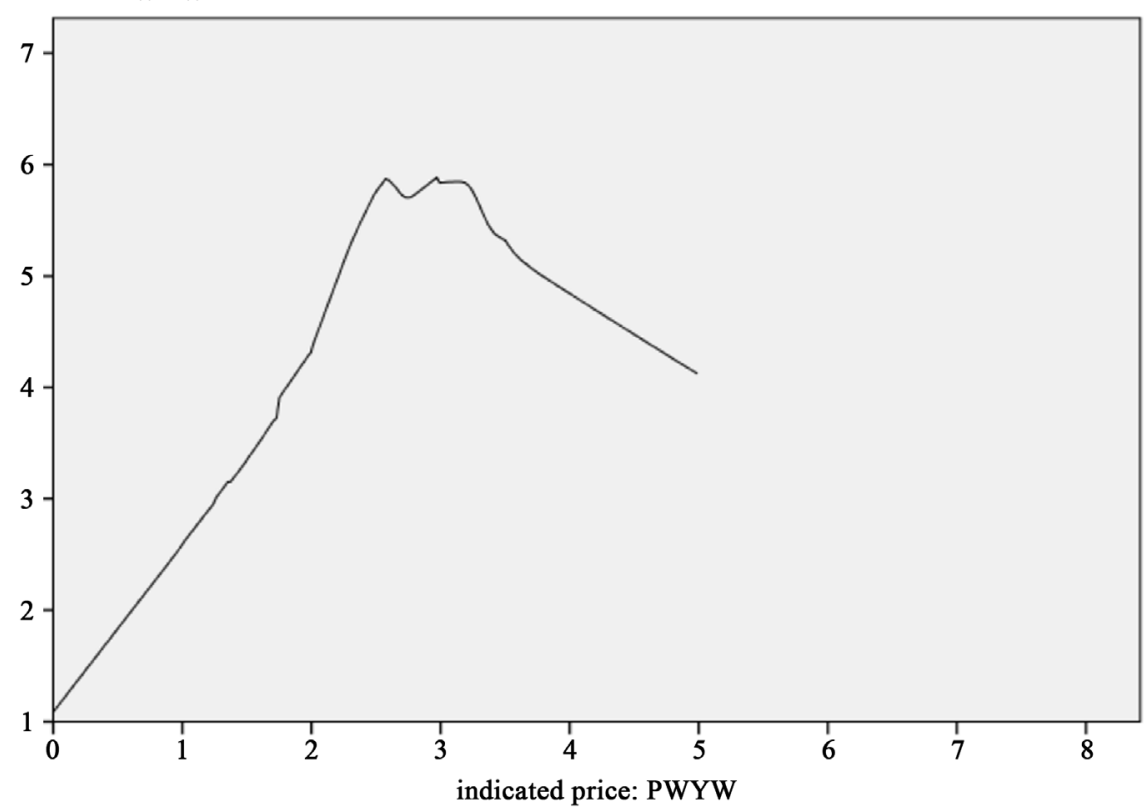

Figure 3. Relationship between the buyer's PPF and his indicated price in PWYW in Poland. Loess, $\mathrm{f}=0.5$.

Table 8. $z$-scores of the difference between the converted correlation of price level and PPF in PWYW between countries.

\begin{tabular}{cccccc}
\hline & & Australia & Germany & Poland & USA \\
\hline$n=77$ & \multirow{2}{*}{ Australia } & & $z=0.938$ & $z=1.372$ & $z=0.594$ \\
$r=0.271$ & & & $p=0.348$ & $p=0.17$ & $p=0.552$ \\
$n=83$ & \multirow{2}{*}{ Germany } & $z=0.938$ & & $z=2.318$ & $z=0.37$ \\
$r=0.126$ & & $p=0.348$ & & $p=0.02$ & $p=0.712$ \\
$n=72$ & \multirow{2}{*}{ Poland } & $z=1.372$ & $z=2.318$ & & $z=2.006$ \\
$r=0.468$ & & $p=0.17$ & $p=0.02$ & & $p=0.044$ \\
$n=90$ & \multirow{2}{*}{ USA } & $z=0.594$ & $z=0.37$ & $z=2.006$ & \\
$r=0.182$ & & $p=0.552$ & $p=0.712$ & $p=0.044$ & \\
\hline
\end{tabular}

Table 9. Between-subjects effects in two-way independent ANOVA.

\begin{tabular}{ccccccc}
\hline \multicolumn{7}{c}{ Tests of between-subjects effects } \\
\hline \multicolumn{7}{c}{ Dependent variable: PPF in PWYW } \\
Source & $\begin{array}{c}\text { Type III sum } \\
\text { of squares }\end{array}$ & df & $\begin{array}{c}\text { Mean } \\
\text { square }\end{array}$ & $F$ & Sig. & $\begin{array}{c}\text { Partial eta } \\
\text { squared }\end{array}$ \\
\hline Corrected model & $100.343^{\mathrm{a}}$ & 11 & 9.122 & 3.017 & 0.001 & 0.097 \\
Intercept & 6356.715 & 1 & 6356.715 & 2102.263 & 0.000 & 0.871 \\
@Scenario & 53.195 & 2 & 26.597 & 8.796 & 0.000 & 0.054 \\
Country & 41.298 & 3 & 13.766 & 4.553 & 0.004 & 0.042 \\
@Scenario * country & 17.160 & 6 & 2.860 & 0.946 & 0.462 & 0.018 \\
Error & 937.362 & 310 & 3.024 & & & \\
Total & 7703.000 & 322 & & & & \\
Corrected total & 1037.705 & 321 & & & & \\
\hline
\end{tabular}

a. $R$ Squared $=0.097$ (Adjusted $R$ Squared $=0.065)$. 


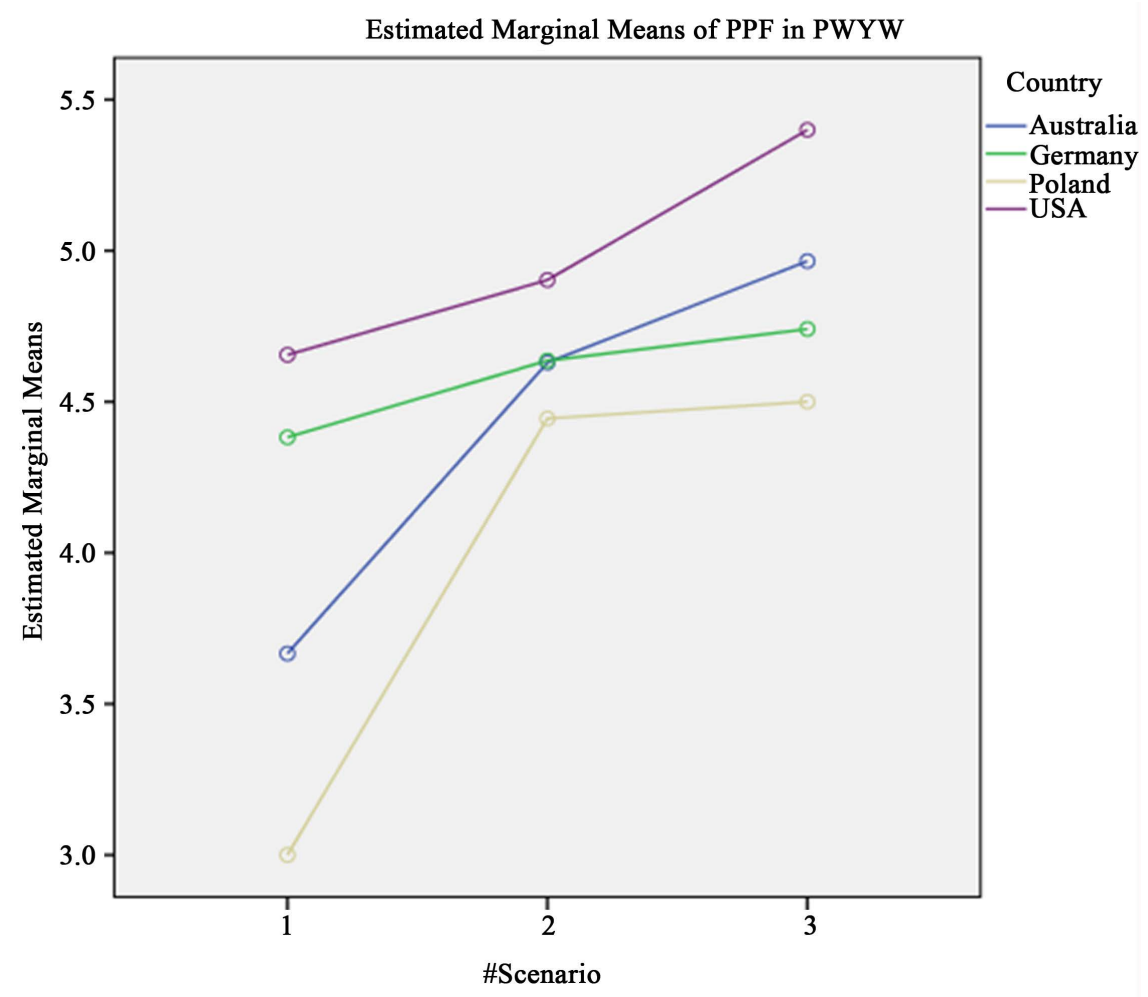

Figure 4. Profile plot for PPF in PWYW per scenario and country.

Table 10. PPF per scenario via a Duncan post hoc test.

\begin{tabular}{cccc}
\hline \multicolumn{4}{c}{ PPF in PWYW } \\
\hline \multicolumn{3}{c}{ Duncan $^{\mathrm{a}, \mathrm{b}, \mathrm{c}}$} \\
\cline { 3 - 4 } Scenario & $N$ & \multicolumn{2}{c}{ Subset } \\
\hline 1 & 105 & 4.038 & 2 \\
2 & 107 & & 4.664 \\
3 & 110 & & 4.927 \\
Sig. & & 1.000 & 0.268 \\
\hline
\end{tabular}

Means for groups in homogeneous subsets are displayed, based on observed means. The error term is Mean Square $($ Error $)=3.024$. a. Uses Harmonic Mean Sample Size $=107.294$. b. The group sizes are unequal. The harmonic mean of the group sizes is used. Type I error levels are not guaranteed. c. Alpha $=0.05$.

Table 11. PPF per country via a Duncan post hoc test.

\begin{tabular}{cccc}
\hline & \multicolumn{3}{c}{ PPF in PWYW } \\
\hline & $N$ & Duncan $^{\mathrm{a}, \mathrm{b}, \mathrm{c}}$ & \\
\cline { 3 - 4 } Country & & \multicolumn{2}{c}{ Subset } \\
\hline Poland & 72 & 4.042 & 2 \\
Australia & 77 & 4.494 & 4.494 \\
Germany & 83 & 4.566 & 4.566 \\
USA & 90 & & 4.989 \\
Sig. & & 0.072 & 0.089 \\
\hline
\end{tabular}

Means for groups in homogeneous subsets are displayed, based on observed means. The error term is Mean Square $($ Error $)=3.024$. a. Uses Harmonic Mean Sample Size $=79.944$. b. The group sizes are unequal. The harmonic mean of the group sizes is used. Type I error levels are not guaranteed. c. Alpha $=0.05$. 
There was a non-significant interaction effect between scenario and country on PPF, $F(6,310)=2.86, p=0.462, \omega^{2}=0.018$.

\section{Discussion}

\subsection{Interpretation of the Results}

The aim of this study was to investigate PPF as well as to identify influences on PPF within the pricing mechanism PWYW. Therefore, a questionnaire-based survey was carried out. It was hypothesized that PPF in a PWYW situation is significantly higher than PPF in an OPS situation. With a statistical significance of $p<0.001$, the result supports this hypothesis. This is in line with studies by Weiner [50], Chandran and Morwitz [18], and Haws and Bearden [20], who showed that buyer's participation in the price building process leads to higher PPF. In this study, PPF in a PWYW context is $26 \%$ higher than PPF in an OPS context. Although the PPF in a PWYW situation is higher than PPF in an OPS situation, the result does not support Dorn's [29] assumption that the price mechanism PWYW entails a maximum amount of PPF, because PPF in PWYW is rated with an average of 4.55 out of 7 . The buyer's perceived fairness of a price could be higher. This study cannot give any indications if there are price building mechanisms in which PPF is higher than in PWYW, since this study solely comprises investigations on PPF in PWYW and OPS conditions.

The first potential determinant of PPF in a PWYW context examined was the amount paid in PWYW conditions. Bearden et al. [68] and Maxwell [69] showed a negative correlation between PPF and price paid in OPS conditions which is statistically supported by this study, having said that it must be considered that PPF in OPS only shares $1.7 \%$ of the variability in the indicated price. The loess curve shows that PPF only decreases up to an amount paid of approximately $\$ 5$. This is an unexpected observation that cannot be set into relation to other studies yet. Further and more detailed investigations of the correlation of offer price and PPF in OPS conditions are necessary to find reasons for the course of the loess curve observed.

In contrast to the negative correlation of price paid and PPF in OPS conditions and in contrast to $\mathrm{H}_{2 \mathrm{~b}}$ (that PPF also correlates negatively with the amount paid in PWYW conditions), the correlation between the variables in a PWYW context is statistically significantly positive with $p<0.001$. Thus, $\mathrm{H}_{2 \mathrm{~b}}$ has to be rejected. However, the price paid cannot be removed from the list of potential determinants for PPF in PWYW. In fact, the results rather suggest that the indicated price is a determinant for PPF, but the other way around from what was expected. The higher the buyer's indicated price, the higher his PPF.

Interestingly, a price paid of $\$ 0$ in PWYW is, according to the loess curves in Figure 1 and Figure 2, perceived as less fair than a price paid of $\$ 4$ in OPS conditions. The increasing loess curve in a PWYW context, contrary to the decreasing loess curve in an OPS context, indicates that the concept of PPF varies depending on price setting conditions. Whereas in OPS conditions, buyers evaluate the fairness of a price the seller determines, they evaluate the fairness of their 
own determined price in PWYW. However, the results of this study suggest that the subject of evaluation for PPF in PWYW may not be the price itself, but rather the subject who determines the price. The subject of evaluation may switch from the seller to the buyer accordingly. Thus, the price might just be an indication for the buyer if the subject who determines the price is fair. This mental model is in line with results of studies of Gneezy, Gneezy, Riener, and Nelson [88] and Jang and Chu [23], who showed that consumers pay higher prices in PWYW because they care more about their self-image rather than their loss to the companies. Accordingly, fairness is attributed to the determining person instead of to the price itself.

Examining the loess curve of price level and PPF in PWYW shows that PPF increases up to an amount paid of approximately $\$ 3$. The prices between $\$ 0$ and $\$ 3$ may be perceived as less fair, because the buyer feels like he is not paying a fair amount towards the seller. Reaching an amount of $\$ 3$, the loess curve slightly decreases. A price level could have been reached that is perceived as fair towards the seller. Higher indicated prices seem not to increase the buyer's PPF in PWYW.

After having examined the correlation between PPF and the price paid, it was investigated if the degree of social interaction influences the buyer's PPF in a PWYW situation. $\mathrm{H}_{3}$ assumed that PPF changes with a varying degree of social interaction. Indeed, in the anonymous online payment situation without social interaction PPF was significantly lower than PPF in a scenario including direct contact with either only McDonald's employees or McDonald's employees and friends. Thus, $\mathrm{H}_{3}$ was supported. Having friends that were watching in Scenario 3 increased the PPF slightly by $5.6 \%$, but this difference was not significant. The fact that PPF increases with an increasing amount of social interaction could be expected due to the positive relationship of PPF and price paid observed in $\mathrm{H}_{2 \mathrm{a}}$ in combination with the positive effect of social interaction on the buyer's willingness-to-pay in PWYW situations according to Dorn [29]. This result supports the findings of Kim et al. [14] and Dorn and Suessmair [28]: The social distance between buyer and seller does influence the buyer's perception and behaviour. In PWYW situations, PPF increases with an increasing degree of social interaction.

Following the result of $\mathrm{H}_{2 \mathrm{~b}}$, it can be assumed that the amount paid has an influence on the buyer's PPF. $\mathrm{H}_{4 \mathrm{a}}$ is related to $\mathrm{H}_{2 \mathrm{~b}}$ and assumes differences of the influence of price level on the buyer's PPF in a PWYW context between countries. The test results of $\mathrm{H}_{4 \mathrm{a}}$ show that the influence of price level indeed varies between countries. The correlation between price level and PPF in Poland is significantly higher than the correlation in Germany $(p=0.02)$ and the correlation in the USA $(p=0.044)$. Taking a closer look at Poland's loess curve shows that the PPF of Polish participants changes more rapidly depending on their determined price. This indicates that they are more sensitive to the amount they pay. The price of approximately $\$ 3$ seems to be the critical price where the course of PPF switches from the price getting more fair to the price getting less fair with 
increasing prices. However, as this study is somewhat explorative in character, these results should be seen as a first indication for the underlying processes. Further investigation between and within the countries are necessary for finding the causes of the observed phenomena.

$\mathrm{H}_{4 b}$ assumed that the influence of the degree of social interaction varies between countries. The results reveal a main effect for scenario ${ }^{14}$ and a main effect for country. PPF in the USA is significantly higher than PPF in Poland, which is in line with the findings of Mattila and Choi [70] and Bolton et al. [71], who suggested cross-cultural differences in PPF. Dorn [29] showed that for US citizens, loyalty has a significantly higher influence on PWYW decisions compared to Polish citizens. As such, the American origin of McDonald's may be the reason for the statistically significantly higher PPF of participants from the USA.

However, results did not support $\mathrm{H}_{4 b}$, as it investigated whether the influence of the degree of social interaction on buyer's PPF varies between countries. Results did not show a significant interaction effect between scenario and country $(p=0.462)$. Firstly, this suggests that the influence of the degree of social interaction does not vary between countries, but it must be considered that this study only comprises countries with very similar cultures. Australia, Germany, Poland, and the USA are all individualistic societies. Mattila and Choi [70] showed differences in PPF between the individualistic USA and the culturally collectivist South Korea, and Bolton et al. [71] showed differences in PPF between USA and China, which is characterised as collectivist country as well [89]. In conclusion, results show that the influence of degree of social interaction on the buyer's PPF is stable across countries with a western culture.

\subsection{Limitations and Outlook for Further Research}

The methodological approach of this study shall be reflected critically in order to demonstrate existing limitations and provide proposals for future research.

It is important to keep in mind that the data was collected in a purely hypothetical scenario. The participants imagined the PWYW situation and did not pay the indicated price in real life. If they would have had to pay the price they determined for a Big Mac, the participants' price determination could have been different. Additionally, a Big Mac is a product that is purchased and consumed when one is hungry. The indicated PWYW price for a Big Mac as well as the perception of price fairness could vary depending on if someone is craving for food or not. It would be interesting to see if the results of this study align with studies conducted in real life situations. Thus, future research should not just examine PPF in hypothetical settings. Studies in local stores or online experiments, where the buyer actually pays a price and receives a product, could be conceived.

It should also be considered that there might have been different perceptions regarding McDonald's Big Mac between countries. The company McDonalds as a global operating chain or the product Big Mac as a burger may be afflicted with

${ }^{14}$ The main effect for scenario is already discussed in $\mathrm{H}_{3}$. 
differing images between countries. Future research should investigate PPF in PWYW using different reference products. Additionally, to examine differences in PPF not only between countries but also between different cultures, research should be expanded to include non-western societies.

Finally, because the results of this study suggest that the mental concept of PPF in PWYW is different from the concept of PPF in OPS, the consequences of PPF in PWYW must be re-examined. It is unsure, if the benefits of PPF, including a positive influence on the customer's intent to purchase [7] [8], a positive influence on customer satisfaction [9] [10], a positive influence on customer loyalty [11], a positive influence on the buyer's attitude towards the seller [12], and perceived quality [13], are still valid within PWYW conditions. Previous research showed that PPF is important for sellers because of such positive effects, whereas perceived price unfairness leads to massive negative consequences. However, both consequences for PPF as well as consequences for perceived price unfairness have to be newly investigated in PWYW due to the buyer's varying mental model of PPF depending on the price building mechanism.

\section{References}

[1] Chung, J.Y. and Petrick, J.F. (2015) Measuring Price Fairness: Development of a Multidimensional Scale. Journal of Travel \& Tourism Marketing, 32, 907-922. https://doi.org/10.1080/10548408.2015.1063894

[2] Diller, H. (2008) Preispolitik. 4th Edition, Kohlhammer, Stuttgart.

[3] Wübker, G. and Lauszus, D. (2005) Ertragssteigerung durcheffektivere PricingProzesse: Von der Preisstrategie bis zur-durchsetzung. Bonn. http://studylibde.com/doc/1554291/ertragssteigerung-durch-effektivere-pricing

[4] Adamy, J. (2000) E-Tailer Price Tailoring May Be Wave of Future. Chicago Tribune.

[5] Fassnacht, M. and Mahadevan, J. (2010) Grundlagen der Preisfairness-Bestand0 saufnahme und Ansätze für zukünftige Forschung. Journal für Betriebswirtschaft, 60, 295-326. https://doi.org/10.1007/s11301-010-0067-5

[6] Xia, L., Monroe, K.B. and Cox, J.L. (2004) The Price Is Unfair! A Conceptual Framework of Price Fairness Perceptions. Journal of Marketing, 68, 1-15. https://doi.org/10.1509/jmkg.68.4.1.42733

[7] Daskalopoulou, I. (2008) Fairness Perceptions and Observed Consumer Behavior: Results of a Partial Observability Model. The Journal of Socio-Economics, 37, 3144.

[8] Daskalopoulou, I. and Petrou, A. (2006) Consumers' Expenditures and Perceived Price Fairness. International Journal of Social Economics, 33, 766-780. https://doi.org/10.1108/03068290610705670

[9] Oliver, R.L. and Swan, J.E. (1989) Consumer Perceptions of Interpersonal Equity and Satisfaction in Transactions: A Field Survey Approach. Journal of Marketing, 53, 21. https://doi.org/10.2307/1251411

[10] Oliver, R.L. and Swan, J.E. (1989) Equity and Disconfirmation Perceptions as Influences on Merchant and Product Satisfaction. Journal of Consumer Research, 16, 372. https://doi.org/10.1086/209223

[11] Bei, L.-T. and Chiao, Y.-C. (2001) An Integrated Model for the Effects of Perceived Product, Perceived Service Quality, and Perceived Price Fairness on Consumer Sat- 
isfaction and Loyalty. Journal of Consumer Satisfaction, Dissatisfaction and Complaining Behavior, 14, 125.

[12] Maxwell, S. (2002) Rule-Based Price Fairness and Its Effect on Willingness to Purchase. Journal of Economic Psychology, 23, 191-212.

[13] Oh, H. (2003) Price Fairness and Its Asymmetric Effects on Overall Price, Quality, and Value Judgments: The Case of an Upscale Hotel. Tourism Management, 24, 387-399.

[14] Kim, J.-Y., Natter, M. and Spann, M. (2009) Pay What You Want: A New Participative Pricing Mechanism. Journal of Marketing, 73, 44-58.

https://doi.org/10.1509/jmkg.73.1.44

[15] Kim, J.-Y., Natter, M. and Spann, M. (2014) Sampling, Discounts or Pay-WhatYou-Want: Two Field Experiments. International Journal of Research in Marketing, Forthcoming, 31, 327-334.

[16] Kim, J.-Y., Natter, M. and Spann, M. (2010) Kish: Where Customers Pay as They Wish. Review of Marketing Science, 8. https://doi.org/10.2202/1546-5616.1118

[17] Riener, G. and Traxler, C. (2012) Norms, Moods, and Free Lunch: Longitudinal Evidence on Payments from a Pay-What-You-Want Restaurant. The Journal of Socio-Economics, 41, 476-483.

[18] Chandran, S. and Morwitz, V.G. (2005) Effects of Participative Pricing on Consumers' Cognitions and Actions: A Goal Theoretic Perspective. Journal of Consumer Research, 32, 249-259. https://doi.org/10.1086/432234

[19] Schmidt, K.M., Spann, M. and Zeithammer, R. (2015) Pay What You Want as a Marketing Strategy in Monopolistic and Competitive Markets. Management Science, 61, 1217-1236. https://doi.org/10.1287/mnsc.2014.1946

[20] Haws, K.L. and Bearden, W.O. (2006) Dynamic Pricing and Consumer Fairness Perceptions. Journal of Consumer Research, 33, 304-311. https://doi.org/10.1086/508435

[21] Mankiw, N.G. and Taylor, M.P. (2012) Grundzüge der Volkswirtschaftslehre. 5th Edition, Schäffer-Poeschel, Stuttgart.

[22] Chao, Y., Fernandez, J. and Nahata, B. (2015) Pay-What-You-Want Pricing: Can It Be Profitable? Journal of Behavioral and Experimental Economics, 57, 176-185.

[23] Jang, H. and Chu, W. (2012) Are Consumers Acting Fairly Toward Companies? An Examination of Pay-What-You-Want Pricing. Journal of Macromarketing, 32, 348360. https://doi.org/10.1177/0276146712448193

[24] Leon, F.J., Noguera, J.A. and Tena-Sanchez, J. (2012) How Much Would You Like to Pay? Trust, Reciprocity and Prosocial Motivations in El Trato. Social Science Information, 51, 389-417. https://doi.org/10.1177/0539018412441756

[25] Morrow, G. (2009) Radiohead's Managerial Creativity. Convergence: The International Journal of Research into New Media Technologies, 15, 161-176. https://doi.org/10.1177/1354856508101581

[26] Kim, J.-Y., Kaufmann, K. and Stegemann, M. (2014) The Impact of Buyer-Seller Relationships and Reference Prices on the Effectiveness of the Pay What You Want Pricing Mechanism. Marketing Letters, 25, 409-423.

https://doi.org/10.1007/s11002-013-9261-2

[27] Hilbert, L.P. and Suessmair, A. (2015) The Effects of Social Interaction and Social Norm Compliance in Pay-What-You-Want Situations. AJIBM, 5, 548-556. https://doi.org/10.4236/ajibm.2015.58054

[28] Dorn, T. and Suessmair, A. (2016) Is It Really Worth It? A Test of Pay-What-YouWant Pricing Strategies in a German Consumer Behaviour Context. GBER, 18, 82. 
https://doi.org/10.1504/GBER.2016.073321

[29] Dorn, T. (2015) Relative Importance of Determinants in Pay-What-You-Want Pricing Decisions-A Cross-Cultural Study. Masterarbeit, Wirtschafts-und Sozialwissenschaftliche Fakultät, Universität zu Köln, Köln.

[30] Kukar-Kinney, M., Xia, L. and Monroe, K.B. (2007) Consumers' Perceptions of the Fairness of Price-Matching Refund Policies. Journal of Retailing, 83, 325-337.

[31] Wild, M. (2013) Preisfairness: Ein State of the Art Review der theoretischen und empirischen Forschung. GRIN Verlag GmbH, München.

[32] Kahneman, D., Knetsch, J.L. and Thaler, R. (1986) Fairness as a Constraint on Profit Seeking: Entitlements in the Market. The American Economic Review, 76, 728-741.

[33] Kahneman, D., Knetsch, J.L. and Thaler, R.H. (1986) Fairness and the Assumptions of Economics. The Journal of Business, 59, S285-S300. https://doi.org/10.1086/296367

[34] Adams, J.S. (1965) Inequity in Social Exchange. In: Berkowitz, L., Ed., Advances in Experimental Social Psychology, Vol. 2, Advances in Experimental Social Psychology, Academic Press, New York, London, 267-299.

[35] Adams, J.S. (1963) Towards an Understanding of Inequity. The Journal of Abnormal and Social Psychology, 67, 422-436. https://doi.org/10.1037/h0040968

[36] Homans, G.C. (1974) Social Behavior: Its Elementary Forms. Revised Edition.

[37] Festinger, L. (1962) A Theory of Cognitive Dissonance. Stanford University Press, Redwood City.

[38] Bechwati, N.N., Sheth, J.N. and Sisodia, R.S. (2005) Consumers' Perceptions of Pricing Unfairness. Advances in Consumer Research, 32, 388.

[39] Bolton, L.E., Warlop, L. and Alba, J.W. (2003) Consumer Perceptions of Price (Un) Fairness. Journal of Consumer Research, 29, 474-491.

https://doi.org/10.1086/346244

[40] Campbell, M.C. (2007) Says Who? How the Source of Price Information and Affect Influence Perceived Price (Un) Fairness. Journal of Marketing Research, 44, 261 271. https://doi.org/10.1509/jmkr.44.2.261

[41] Frey, B.S. and Pommerehne, W.W. (1993) On the Fairness of Pricing-An Empirical Survey among the General Population. Journal of Economic Behavior \& Organization, 20, 295-307.

[42] Huang, J.-H., Chang, C.-T. and Chen, C.Y.-H. (2005) Perceived Fairness of Pricing on the Internet. Journal of Economic Psychology, 26, 343-361.

[43] Kimes, S.E. (1994) Perceived Fairness of Yield Management. The Cornell Hotel and Restaurant Administration Quarterly, 35, 22-29.

[44] Herrmann, A., Wricke, M. and Huber, F. (2000) Kundenzufriedenheit durch Preisfairness. Marketing ZfP, 22, 131-143.

[45] Matzler, K., Würtele, A. and Renzl, B. (2006) Dimensions of Price Satisfaction: A Study in the Retail Banking Industry. International Journal of Bank Marketing, 24, 216-231. https://doi.org/10.1108/02652320610671324

[46] Padula, G. and Busacca, B. (2005) The Asymmetric Impact of Price-Attribute Performance on Overall Price Evaluation. International Journal of Service Industry Management, 16, 28-54. https://doi.org/10.1108/09564230510587140

[47] Martins, M. and Monroe, K.B. (1994) Perceived Price Fairness: A New Look at an Old Construct. Advances in Consumer Research, 21. 
[48] Kalapurakal, R., Dickson, P.R. and Urbany, J.E. (1991) Perceived Price Fairness and Dual Entitlement. Advances in Consumer Research, 18.

[49] Dickson, P.R. and Kalapurakal, R. (1994) The Use and Perceived Fairness of Price-Setting Rules in the Bulk Electricity Market. Journal of Economic Psychology, 15, 427-448.

[50] Weiner, B. (1985) An Attributional Theory of Achievement Motivation and Emotion. Psychological Review, 92, 548-573. https://doi.org/10.1037/0033-295X.92.4.548

[51] Bolton, L.E. and Alba, J.W. (2006) Price Fairness: Good and Service Differences and the Role of Vendor Costs. Journal of Consumer Research, 33, 258-265. https://doi.org/10.1086/506306

[52] Campbell, M.C. (1999) Pricing Strategy \& Practice "Why Did You Do That? The Important Role of Inferred Motive in Perceptions of Price Fairness. Journal of Product \& Brand Management, 8, 145-153. https://doi.org/10.1108/10610429910266995

[53] Campbell, M.C. (1999) Perceptions of Price Unfairness: Antecedents and Consequences. Journal of Marketing Research, 36, 187. https://doi.org/10.2307/3152092

[54] Frey, B.S. and Gygi, B. (1988) Die Fairness von Preisen. Swiss Journal of Economics and Statistics, 124, 519-541.

[55] Gielissen, R., Dutilh, C.E. and Graafland, J.J. (2007) Perceptions of Price Fairness: An Empirical Research. Business \& Society, 47, 370-389. https://doi.org/10.1177/0007650308316937

[56] Kachelmeier, S.J., Limberg, S.T. and Schadewald, M.S. (1991) Fairness in Markets: A Laboratory Investigation. Journal of Economic Psychology, 12, 447-464.

[57] Martin, W.C., Ponder, N. and Lueg, J.E. (2009) Price Fairness Perceptions and Customer Loyalty in a Retail Context. Journal of Business Research, 62, 588-593.

[58] Schein, A. (2002) Concern for Fair Prices in the Israeli Housing Market. Journal of Economic Psychology, 23, 213-230.

[59] Urbany, J.E., Madden, T.J. and Dickson, P.R. (1989) All's Not Fair in Pricing: An Initial Look at the Dual Entitlement Principle. Marketing Letters, 1, 17-25. https://doi.org/10.1007/BF00436145

[60] Vaidyanathan, R. and Aggarwal, P. (2003) Who Is the Fairest of Them All? An Attributional Approach to Price Fairness Perceptions. Journal of Business Research, 56, 453-463.

[61] Anderson, E.T. and Simester, D.I. (2008) Research Note-Does Demand Fall When Customers Perceive That Prices Are Unfair? The Case of Premium Pricing for Large Sizes. Marketing Science, 27, 492-500. https://doi.org/10.1287/mksc.1070.0323

[62] Choi, S. and Mattila, A.S. (2009) Perceived Fairness of Price Differences across Channels: The Moderating Role of Price Frame and Norm Perceptions. The Journal of Marketing Theory and Practice, 17, 37-48. https://doi.org/10.2753/MTP1069-6679170103

[63] Grewal, D., Hardesty, D.M. and Iyer, G.R. (2004) The Effects of Buyer Identification and Purchase Timing on Consumers' Perceptions of Trust, Price Fairness, and Repurchase Intentions. Journal of Interactive Marketing, 18, 87-100. https://doi.org/10.1002/dir.20024

[64] Kimes, S.E. and Wirtz, J. (2002) Perceived Fairness of Demand-Based Pricing for Restaurants. The Cornell Hotel and Restaurant Administration Quarterly, 43, 3137. 
[65] Mahadevan, J. (2010) Wahrgenommene Preisfairness bei personenbezogener Preisdifferenzierung: Peter Lang.

[66] Estalami, H., Tsai, D. and Lee, H. (2007) Will You Care When You Pay More? The Negative Side of Targeted Promotions. Journal of Product \& Brand Management, 16, 481-491. https://doi.org/10.1108/10610420710834931

[67] Kamen, J.M. and Toman, R.J. (1970) Psychophysics of Prices. Journal of Marketing Research, 7, 27-35. https://doi.org/10.2307/3149503

[68] Bearden, W.O., Carlson, J.P. and Hardesty, D.M. (2003) Using Invoice Price Information to Frame Advertised Offers. Journal of Business Research, 56, 355-366.

[69] Maxwell, S. (2005) Hyperchoice and High Prices: An Unfair Combination. Journal of Product \& Brand Management, 14, 448-454. https://doi.org/10.1108/10610420510633396

[70] Mattila, A.S. and Choi, S. (2006) A Cross-Cultural Comparison of Perceived Fairness and Satisfaction in the Context of Hotel Room Pricing. International Journal of Hospitality Management, 25, 146-153.

[71] Bolton, L.E., Keh, H.T. and Alba, J.W. (2010) How Do Price Fairness Perceptions Differ Across Culture? Journal of Marketing Research, 47, 564-576. https://doi.org/10.1509/jmkr.47.3.564

[72] Babin, B.J., Hardesty, D.M. and Suter, T.A. (2003) Color and Shopping Intentions: The Intervening Effect of Price Fairness and Perceived Affect. Journal of Business Research, 56, 541-551.

[73] Collie, T., Bradley, G. and Sparks, B.A. (2002) Fair Process Revisited: Differential Effects of Interactional and Procedural Justice in the Presence of Social Comparison Information. Journal of Experimental Social Psychology, 38, 545-555.

[74] Darke, P.R. and Dahl, D.W. (2003) Fairness and Discounts: The Subjective Value of a Bargain. Journal of Consumer Psychology, 13, 328-338.

https://doi.org/10.1207/S15327663JCP1303_13

[75] Hardesty, D.M. and Suter, T.A. (2005) E-Tail and Retail Reference Price Effects. Journal of Product \& Brand Management, 14, 129-136. https://doi.org/10.1108/10610420510592626

[76] Huppertz, J.W., Arenson, S.J. and Evans, R.H. (1978) An Application of Equity Theory to Buyer-Seller Exchange Situations. Journal of Marketing Research, 15, 250. https://doi.org/10.2307/3151255

[77] Kimes, S.E. (2002) Perceived Fairness of Yield Management. The Cornell Hotel and Restaurant Administration Quarterly, 43, 21-30.

[78] Oliver, R.L. and Shor, M. (2003) Digital Redemption of Coupons: Satisfying and Dissatisfying Effects of Promotion Codes. Journal of Product \& Brand Management, 12, 121-134. https://doi.org/10.1108/10610420310469805

[79] Suter, T.A. and Hardesty, D.M. (2005) Maximizing Earnings and Price Fairness Perceptions in Online Consumer-to-Consumer Auctions. Journal of Retailing, 81, 307-317.

[80] Monroe, K.B. (2003) Pricing: Making Profitable Decisions. 3rd Edition, McGraw-Hill/Irwin, Boston, London.

[81] Herrmann, A., Xia, L., Monroe, K.B. and Huber, F. (2007) The Influence of Price Fairness on Customer Satisfaction: An Empirical Test in the Context of Automobile Purchases. Journal of Product \& Brand Management, 16, 49-58. https://doi.org/10.1108/10610420710731151

[82] Tukey, J.W. (1977) Exploratory Data Analysis.

[83] Carling, K. (2000) Resistant Outlier Rules and the Non-Gaussian Case. Computa- 
tional Statistics \& Data Analysis, 33, 249-258.

[84] Andreß, H.-J. (2010) Analyse Kategorialer Daten. In: Wolf, C. and Best, H., Eds., Handbuch der sozialwissenschaftlichen Datenanalyse, VS Verlag für Sozialwissenschaften/Springer Fachmedien Wiesbaden GmbH Wiesbaden, Wiesbaden, 421-454. https://doi.org/10.1007/978-3-531-92038-2_18

[85] Norman, G. (2010) Likert Scales, Levels of Measurement and the "Laws" of Statistics. Advances in Health Sciences Education: Theory and Practice, 15, 625-632. https://doi.org/10.1007/s10459-010-9222-y

[86] Field, A. (2013) Discovering Statistics Using IBM SPSS Statistics: And Sex and Drugs and Rock "N" Roll, 4th Edition, Sage, Los Angeles, London, New Delhi.

[87] Jacoby, W.G. (2000) Loess: A Nonparametric, Graphical Tool for Depicting Relationships between Variables. Electoral Studies, 19, 577-613.

[88] Gneezy, A., Gneezy, U., Riener, G. and Nelson, L.D. (2012) Pay-What-You-Want, Identity, and Self-Signaling in Markets. Proceedings of the National Academy of Sciences of the United States of America, 109, 7236-7240.

https://doi.org/10.1073/pnas.1120893109

[89] Earley, P.C. (1989) Social Loafing and Collectivism: A Comparison of the United States and the People's Republic of China. Administrative Science Quarterly, 34, 565. https://doi.org/10.2307/2393567

Submit or recommend next manuscript to SCIRP and we will provide best service for you:

Accepting pre-submission inquiries through Email, Facebook, LinkedIn, Twitter, etc. A wide selection of journals (inclusive of 9 subjects, more than 200 journals) Providing 24-hour high-quality service User-friendly online submission system Fair and swift peer-review system Efficient typesetting and proofreading procedure Display of the result of downloads and visits, as well as the number of cited articles Maximum dissemination of your research work

Submit your manuscript at: http://papersubmission.scirp.org/ Or contact ajibm@scirp.org 